\title{
Internet-Based Intervention
}

National Cancer Institute

\section{Source}

National Cancer Institute. Internet-Based Intervention. NCI Thesaurus. Code C116522.

Any program that uses the internet to alter, modify, or eliminate a behavior. 